\title{
Giuseppe Antonio Brunelli, François Villon Poeta dei paradossi
}

\section{Paola Cifarelli}

\section{Q OpenEdition}

1 Journals

\section{Edizione digitale}

URL: http://journals.openedition.org/studifrancesi/8194

DOI: 10.4000/studifrancesi.8194

ISSN: 2421-5856

\section{Editore}

Rosenberg \& Sellier

\section{Edizione cartacea}

Data di pubblicazione: 1 mai 2009

Paginazione: 153

ISSN: 0039-2944

\section{Notizia bibliografica digitale}

Paola Cifarelli, «Giuseppe Antonio Brunelli, François Villon Poeta dei paradossi», Studi Francesi [Online], 157 (LIII | I) | 2009, online dal 30 novembre 2015, consultato il 13 janvier 2021. URL: http:// journals.openedition.org/studifrancesi/8194 ; DOI: https://doi.org/10.4000/studifrancesi.8194

Questo documento è stato generato automaticamente il 13 janvier 2021.

\section{(c) (i) (9)}

Studi Francesi è distribuita con Licenza Creative Commons Attribuzione - Non commerciale - Non opere derivate 4.0 Internazionale. 


\title{
Giuseppe Antonio Brunelli, François Villon Poeta dei paradossi
}

\author{
Paola Cifarelli
}

\section{NOTIZIA}

GIUSEPPE ANTONIO BRUNelli, François Villon Poeta dei paradossi, Fasano, Schena, 2008

(«Biblioteca della ricerca, Cultura straniera» 149), pp. 349.

1 Giuseppe Brunelli, che a lungo si è occupato di Villon, ripropone qui il frutto della sua riflessione sulle Rime sparse, che egli ha studiato a più riprese in vari saggi ed articoli. Il lettore troverà il testo francese dei poemi villoniani così come era stato proposto nel commento del 1953; da questo lavoro giovanile è tratta anche la maggior parte della materia riguardante l'interpretazione dei testi, che mostra ancora tutta la sua attualità perché frutto non solo dell'erudizione dell'autore, ma anche della sua sensibilità poetica. Quest'ultima si rivela a pieno nelle traduzioni affiancate ai testi, che G.A.B. pubblicò nel 1968 in Le Ballate di Villon ed altre cose mie. Ciò che muta nel presente lavoro è l'ordine dato ai testi, che modifica in parte l'interpretazione globale del percorso poetico ed umano di Villon. Se il lettore moderno sentirà la mancanza di una 'mise à jour' bibliografica, apprezzerà d'altro lato la finezza dell'interpretazione critica e potrà ricostruire una tappa importante nella storia della critica villoniana.

Il volume si chiude con alcuni saggi brevi riprodotti in appendice: Verga e Villon: un accostamento attuale alla luce della poesia dei proverbi, pp. 295-314; 'C'est l'aage d'un mulet' $e$ 'Je congnois cheval et mulet', pp. 315-326; Suso, "De l'orloge de sapience" e Villon, pp. 327-343; La preriforma, Villon e il v. 29 della ballata 'des proverbes', pp. 344-347; Prime fonti delle "Rime Sparse", pp. 348-349. 